\title{
Discussion: On the use of empirical methods for assessment of filters in embankment dams
}

\author{
H. RÖNNQVIST*, J. FANNIN†, P. VIKLANDER* and L. WANG
}

ICE Publishing: All rights reserved

\section{CONTRIBUTION BY L. WANG}

In the paper under discussion, Rönnqvist et al. (2014) employed the method of Wan \& Fell (2004) to assess the internal stability of filters, and they considered the boundary between stable and unstable soils as the line of 5\% probability of failure. Wan \& Fell (2004) used logistic regression to define contours of equal probability of internal instability. However, the method does not give a clear-cut boundary between internally stable and unstable soils for the dataset they tested (Wan \& Fell, 2008). The suggestion made by Rönnqvist et al. (2014) to employ the line of 5\% probability of failure as the threshold between internally stable and unstable soils may require some verification with experimental data. To do so, some data obtained from the literature were reanalysed according to the Wan \& Fell (2004) adaption. In total, 22 laboratory tests were reanalysed; the data were obtained from the tests reported by Kenney \& Lau (1985), Aberg (1993), Lafleur \& Nguyen (2007), Cividini et al. (2009) (two test samples) and Sadaghiani \& Witt (2011) (one test sample). The results are shown in Fig. 8. It is clear that the boundary line of $5 \%$ probability of failure cannot be considered as a threshold between stable and unstable soils.

Another point is related to Figs 4(a) and 4(b) in the paper under discussion (Rönnqvist et al. (2014). In Figs 4(a) and 4(b), the $x$ and $y$ axes are $h^{\prime \prime}$ and $h^{\prime}$, respectively. However, surprisingly, the distribution of data points in the two plots is not the same.

\section{AUTHORS' REPLY}

We first give consideration to the question posed by the contributor on the distribution of data points in Figs 4(a) and 4(b) of the paper under discussion, because it addresses an informative point that we believe may indeed benefit from a note of clarification. An assessment of the potential for seepage-induced internal instability in, for example, the filter material of a dam usually involves an evaluation of gradation curves obtained from construction records and any subsequent investigations. If more than one empirical method is used for shape analysis of the gradations, then several mostvulnerable curves may be identified from the analyses, owing to the empirical origins of the methods themselves.

To illustrate this point, consider the filter gradation data available for dam \#52 in the database of the paper under discussion. A total of nine gradation curves deemed representative of the filter material were obtained by the authors. Shape analysis using the Burenkova (1993) method

Published online at www.geotechniqueletters.com on 6 August 2015.

*Department of Civil, Environmental and Natural Resources Engineering, Luleå University of Technology, Luleå, Sweden $\dagger$ Department of Civil Engineering, University of British Columbia, Vancouver, Canada

College of Architecture and Civil Engineering, Xi'an University of Science and Technology, Xi'an, China established that seven data points were located in zone III and two data points were in zone II (Fig. 9): no explicit instruction is given by Burenkova (1993) to identify the most vulnerable gradation, which was nominally taken to be that of the centrally located data point in zone III with $D_{90} / D_{15}=$ 80 and $D_{90} / D_{60}=5.7$ (see Fig. 4(a) of the paper under discussion). The probability contours of the Wan \& Fell (2004) adaptation are superimposed on Fig. 9: the most vulnerable point was taken to be that with the greatest probability of instability, for which $D_{90} / D_{15}=86$ and $D_{90} /$ $D_{60}=3.3$ (see Fig. 4(b) of the paper under discussion). Accordingly, the outcome of the two analyses is methodspecific for dam \#52 (Fig. 10) - indeed, it is for similar reasons that 28 of the 80 dams in the database plot with different values of $D_{90} / D_{15}$ and $D_{90} / D_{60}$ in Figs 4(a) and 4(b). For the purposes of making a fully informed comparison, the most vulnerable gradation of dam \#52 obtained using the Kenney \& Lau (1986) method and its Li \& Fannin (2008)

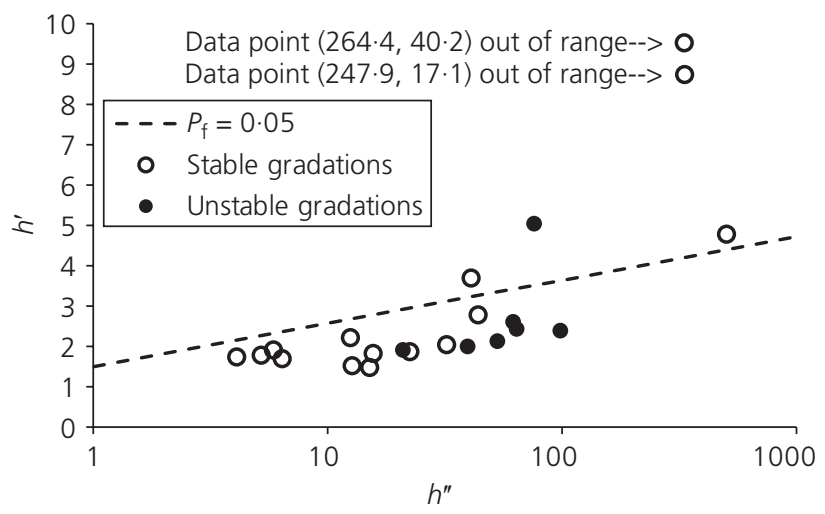

Fig. 8.

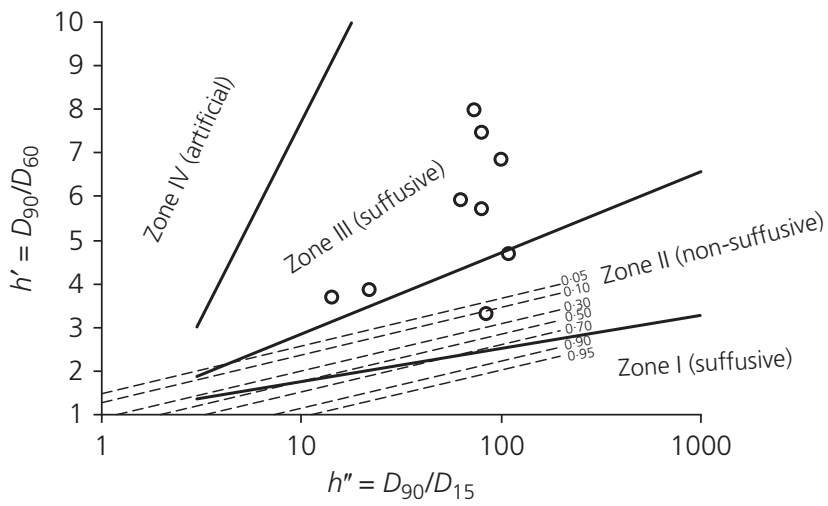

Fig. 9. Burenkova (1993) method and Wan \& Fell (2004) adaptation: dam \#52 gradation points 


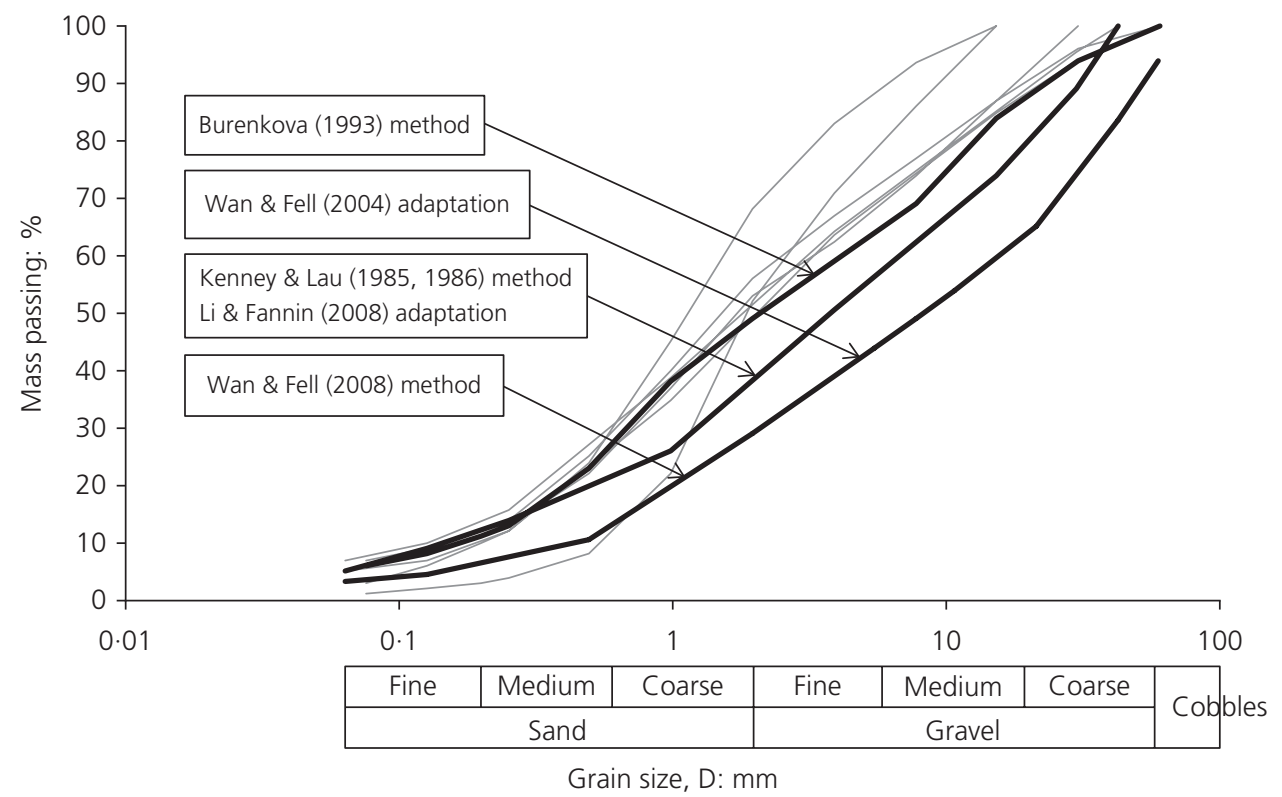

Fig. 10. Most-vulnerable gradations (method-specific analysis) of dam \#52

adaptation, together with the Wan \& Fell (2008) method, are also presented in Fig. 10.

The contributor is correct to report that Wan \& Fell (2004, 2008) observe 'the method does not give a clear-cut boundary between internally stable and unstable soils in the dataset' - a dataset of 58 laboratory test results they had compiled and assessed using the Burenkova (1993) method. Indeed, the finding led Wan \& Fell (2004) to define the contours of equal probability of internal instability that constitute their adaptation of the method. We compared our dataset of gradations from 80 dams ( 23 of which are believed to have had a 'probable occurrence of internal erosion' and 57 of which have exhibited 'no indication to-date of internal erosion') with these contours of equal probability. We found that $87 \%$ of the dams with a probable occurrence of internal erosion had a greater than $5 \%$ probability of internal instability, and that factual observation was reported. However, the contributor is in error to suggest that we advocate the line at $5 \%$ probability as a stability threshold between stable and unstable soils, nor do we believe it should be thus considered. The additional 22 laboratory tests presented in Fig. 8 lend further confidence to this belief. In contrast, we conclude from our study that all dams with one or more filter gradations failing both the Kenney \& Lau (1986) criterion for internal instability and the Foster \& Fell (2001) threshold for excessive erosion have experienced a probable occurrence of internal instability 'suggesting that the unified plot may serve as a screening tool...in engineering practice'.

\section{REFERENCES}

Aberg, B. (1993). Washout of grains from filtered sand and gravel materials. J. Geotech. Engng ASCE, 119, No. 1, 36-53.
Burenkova, V. V. (1993). Assessment of suffusion in non-cohesive and graded soils. In Proc. 1st Int. Conf. on Geo-filters in Geotechnical Engineering. (Brauns, M. Heilbum \& U. Schuler (eds)). Rotterdam: Balkema, pp. 357-360.

Cividini, A., Bonomi, S., Vignati, G. C. \& Gioda, G. (2009). Seepage-induced erosion in granular soil and consequent settlements. Int. J. Geomech. 9, No. 4, 187-194.

Foster, M. A. \& Fell, R. (2001). Assessing embankment dam filters that do not satisfy design criteria. J. Geotech. Geoenviron. Engng 127, No. 4, 398-407.

Kenney, T. C. \& Lau, D. (1985). Internal stability of granular filters. Can. Geotech. J. 22, No. 2, 215-225.

Kenney, T. C. \& Lau, D. (1986). Internal stability of granular filters: reply. Can. Geotech. J. 23, No. 3, 420-423.

Lafleur, J. \& Nguyen, P. H. (2007). Internal stability of particles in dam cores made of cohesionless broadly graded moraines. In Internal erosion of dams and their foundations (R. Fell \& J. J. Fry (eds)). London: Taylor \& Francis, pp. 151-158.

Li, M. \& Fannin, R. J. (2008). Comparison of two criteria for internal stability of granular soil. Can. Geotech. J. 45, No. 9, 1303-1309.

Rönnqvist, H., Fannin, J. \& Viklander, P. (2014). On the use of empirical methods for assessment of filters in embankment dams. Géotech. Lett. 4, No. 4, 272-282, http://dx.doi.org/ 10.1680/geolett.14.00055.

Sadaghiani, M. R. S. \& Witt, K. J. (2011). Variability of the grain size distribution of a soil related to suffusion. In Proc. 3rd Int. Symp. on Geotechnical Risk and Safety (ISGSR) (N. Vogt, B. Schuppener, D. Straub \& G. Bräu (eds)). pp. 239-248.

Wan, C. F. \& Fell, R. (2004). Experimental investigation of internal instability of soils in embankment dams and their foundations. University of New South Wales, Sydney, Australia, UNICIV report no. R-429.

Wan, C. F. \& Fell, R. (2008). Assessing the potential of internal instability and suffusion in embankment dams and their foundations. J. Geotech. Geoenviron. Engng 134, No. 3, 401-407. 